\title{
Mechanisms Underlying Spontaneous Oscillation and Rhythmic Firing in Rat Subthalamic Neurons
}

\author{
Mark D. Bevan ${ }^{1,2}$ and Charles J. Wilson ${ }^{1}$ \\ Department of Anatomy and Neurobiology, University of Tennessee, Memphis, Tennessee 38163, and 2Medical Research \\ Council Anatomical Neuropharmacology Unit, University Department of Pharmacology, Oxford OX1 3TH, United Kingdom
}

Subthalamic neurons drive basal ganglia output neurons in resting animals and relay cortical and thalamic activity to the same output neurons during movement. The first objective of this study was to determine the mechanisms underlying the spontaneous activity of subthalamic neurons in vitro and to gain insight into their resting discharge in vivo. The second objective was to determine the response of subthalamic neurons to depolarizing current injection and how intrinsic properties may shape their response to cortical and thalamic inputs during movement.

Cell-attached and whole-cell recordings were made from subthalamic neurons in brain slices prepared from 3- to 4-week-old rats. The slow, rhythmic discharge of subthalamic neurons was resistant to blockade of excitatory synaptic transmission indicating that intrinsic currents underlie their spontaneous discharge. A persistent sodium current was the source of current during the depolarizing phase of the oscillation. A powerful afterhyperpolarization following each action potential was sufficient to terminate the depolarization. A long duration component of the spike afterhyperpolarization determined the period of the oscillation and was generated by an apaminsensitive calcium-activated potassium current. Calcium entry responsible for that current was associated with action potentials.

Subthalamic neurons exhibited a sigmoidal frequency-current relationship with the steeper portion starting at $\sim 30-40 \mathrm{~Hz}$. This property makes subthalamic neurons more sensitive to input at high firing rates associated with movement than at low rates associated with rest. We propose that the subthreshold persistent sodium current overcomes calcium activated potassium current which accumulates during high frequency firing and underlies the enhanced sensitivity to current $>30 \mathrm{~Hz}$.

Key words: basal ganglia; subthalamic nucleus; persistent sodium current; potassium current; calcium current; afterhyperpolarization; spontaneous activity; f-I relationship; spike frequency adaptation
Glutamatergic neurons of the subthalamic nucleus have been proposed to act as a major driving force of neuronal activity in the output structures of the basal ganglia (Nakanishi et al., 1987; Smith and Parent, 1988; Fujimoto and Kita, 1992, 1993; Rinvik and Ottersen, 1993; Smith et al., 1998). During periods of quiet wakefulness they may, through their tonic activity, sustain the resting inhibitory output of the basal ganglia by driving the tonic activity of GABAergic basal ganglia output neurons in the internal segment of the globus pallidus and the substantia nigra pars reticulata (DeLong et al., 1985; DeLong, 1990; Smith et al., 1998). The resting activity of basal ganglia output neurons is critical to their function, because their other inputs engaged by movement are GABAergic and inhibitory (for references, see Chevalier and Deniau, 1990). In awake, resting monkeys subthalamic neurons fire at $\sim 10-30 \mathrm{~Hz}$ in an irregular manner with a tendency to discharge single spikes or doublets and triplets (DeLong et al., 1985; Matsumara et al., 1992; Wichmann et al., 1994). In brain slice preparations they have been reported to discharge repetitively at similar frequencies but in a more regular manner and predominantly in the single spike mode (Yung et al., 1991; Over-

Received April 14, 1999; revised June 3, 1999; accepted June 10, 1999.

This work was supported by National Institutes of Health-National Institute of Neurological Diseases and Stroke Grant NS 24763, the Medical Research Council (UK), and Wellcome Trust Advanced Training Fellowship 046613/Z/96/Z (M.D.B.). The technical assistance of Brenda Mattix is gratefully acknowledged.

Correspondence should be addressed to Dr, Charles J. Wilson, Department of Anatomy and Neurobiology, 855 Monroe, University of Tennessee, Memphis, TN 38163.

Copyright (C) 1999 Society for Neuroscience $0270-6474 / 99 / 197617-12 \$ 05.00 / 0$ ton and Greenfield, 1995; Beurrier et al., 1999). These findings therefore suggest that subthalamic neurons may possess intrinsic membrane properties, which generate a spontaneous rhythmic firing pattern in the absence of input, and these properties may partly underlie their function as the tonic excitatory input to basal ganglia structures in resting animals. The importance of continuous repetitive discharge by subthalamic neurons to the behavior of the whole animal is exemplified by the fact that experimental or pathological disruption of continuous repetitive firing is invariably associated with a profound hyperkinetic syndrome (for references see Crossman, 1989; DeLong, 1990).

Preceding, during, and after limb or eye movements in awake monkeys, subthalamic neurons may discharge bursts of highfrequency spikes (up to several hundred per second), which can last up to several hundred milliseconds (DeLong et al., 1985; Matsumara et al., 1992; Wichmann et al., 1994). These discharges in turn cause increases in the activity of basal ganglia output neurons leading to increased inhibition of basal ganglia targets (Georgopoulos et al., 1983; Nakanishi et al., 1987; Fujimoto and Kita, 1992, 1993; Turner and Anderson, 1997). It is likely that the monosynaptic cortical and/or thalamic projections to the subthalamic nucleus drive some of the bouts of high-frequency firing during movement, because electrical stimulation of the cortex or thalamus elicits high-frequency firing of subthalamic neurons via glutamatergic neurotransmission acting at AMPA and NMDA receptors (Kitai and Deniau, 1981; Nakanishi et al., 1988; Fujimoto and Kita, 1993; Mouroux and Feger, 1993; Bevan et al., 1995; Mouroux et al., 1995; Clarke and Bolam, 1998). Activation 
of the indirect pathway, which inhibits the external segment of the globus pallidus, may also lead to net excitation of subthalamic neurons during movement via a disinhibitory mechanism (Fujimoto and Kita, 1993; Maurice et al., 1998; Smith et al., 1998). According to a current model of basal ganglia function, the high-frequency discharge of subthalamic neurons during movement is likely to suppress nonselected motor programs or terminate sequences of motor behavior (DeLong, 1990).

Thus subthalamic neurons perform a dual function in the operation of the basal ganglia: they discharge continuously and repetitively at low frequencies, and then during movement, presumably in response to synaptic input, they fire repetitively at much higher frequencies. The first objective of this paper was to determine the nature of the membrane potential oscillation that underlies the spontaneous discharge of the subthalamic neuron. The second objective was to study the response of subthalamic neurons to the injection of depolarizing current and thereby gain insight into their response to excitatory synaptic input.

\section{MATERIALS AND METHODS}

Slice preparation. Standard techniques were used for the preparation of brain slices for recording. Briefly, Sprague Dawley rats of either sex aged 14-27 d were deeply anesthetized with ketamine-xylazine and perfused transcardially with 10-20 ml of ice-cold modified artificial CSF (ACSF), which had been bubbled with $95 \% \mathrm{O}_{2}$ and $5 \% \mathrm{CO}_{2}$ and contained (in $\mathrm{mM}$ ): sucrose, 230; $\mathrm{KCl}, 2.5 ; \mathrm{Na}_{2} \mathrm{HPO}_{4}, 1.25 ; \mathrm{CaCl}_{2}, 0.5, \mathrm{MgSO}_{4}, 10$; and glucose, 10 . The brain was rapidly removed, blocked in either the coronal or sagittal plane, glued to the stage of a Vibroslicer (World Precision Instruments, Sarasota, FL), and immersed in ice-cold modified ACSF. Slices containing the subthalamus were cut at a thickness of $300 \mu \mathrm{m}$ and then transferred to a holding chamber where they were submerged in ACSF, which was continuously bubbled with $95 \% \mathrm{O}_{2}$ and $5 \% \mathrm{CO}_{2}$ and maintained at room temperature $\left(25-30^{\circ} \mathrm{C}\right.$ ) and contained (in $\mathrm{mM}$ ): $\mathrm{NaCl}, 126 ; \mathrm{KCl}, 2.5 ; \mathrm{Na}_{2} \mathrm{HPO}_{4}, 1.25 ; \mathrm{CaCl}_{2}, 2 ; \mathrm{MgSO}_{4}, 2$; and glucose, 10. Slices were held in this chamber for at least $1 \mathrm{hr}$ before recording.

Visualized recording. Individual slices were transferred to the recording chamber and were continuously perfused $(2-3 \mathrm{ml} / \mathrm{min})$ with oxygenated ACSF at room temperature or $35^{\circ} \mathrm{C}$. A $40 \times$ water-immersion objective (Axioskop; Zeiss, Oberkochen, Germany) was used to examine the slice using standard infrared differential interference contrast video microscopy (Stuart et al., 1993). Somatic recordings were made using patch pipettes prepared from thin-wall borosilicate glass (Warner Instrument Co., Hamden, CT) on a P-87 Flaming/Brown electrode puller (Sutter Instrument Co., Novaton, CA). Pipettes were filled with a solution containing (in $\mathrm{mm}$ ): $\mathrm{K}-\mathrm{MeSO}_{4}, 119 ; \mathrm{KCl}, 12 ; \mathrm{MgCl}_{2} \cdot 6 \mathrm{H}_{2} \mathrm{O}, 1$; $\mathrm{CaCl}_{2} \cdot 2 \mathrm{H}_{2} 0,0.1$; HEPES, 10; EGTA, 1 ; $\mathrm{Na}_{2}$ GTP, 0.4; Mg, 1.5; ATP, 2; and biocytin, 5 . The $\mathrm{pH}$ and osmolarity of the intracellular solution were 7.3 and 290-300 mOsm, respectively. The resistance of the filled pipettes ranged from 3 to $7 \mathrm{M} \Omega$, and the junction potential was $5 \mathrm{mV}$. Junction potential was estimated by comparing the potential obtained in slice media with that in the electrode filling solution. Voltage errors attributable to series resistance and junction potential were subtracted off-line. Fast capacitative transients of the pipette were nulled, but there was no compensation of series resistance or whole-cell capacitance. Recordings were made in the cell-attached and whole-cell configurations using an Axopatch 200A or Axopatch 200B amplifier (Axon Instruments, Foster City, CA) in current-clamp, fast current-clamp, and voltage-clamp modes. Signals were filtered at $2-5 \mathrm{kHz}$ and digitized at $2.5-20 \mathrm{kHz}$ using a Digidata 1200 digitizer and pClamp 6.0 software. (Axon Instruments).

Drugs. Drugs were bath-applied at the following concentrations: 100 $\mathrm{nM}$ apamin (Research Biochemicals, Natick, MA), $50 \mu \mathrm{M}(+)$-2-amino5-phosphonopentanoic acid (APV) (Research Biochemicals), $400 \mu \mathrm{M}$ $\mathrm{CdCl}_{2}$ (Sigma, St Louis, MO), 3-5 mM CsCl (Sigma), $20 \mu \mathrm{M} 6$, 7-dinitroquinoxaline-2,3-dione (DNQX) (Research Biochemicals), and $100 \mu \mathrm{M} \mathrm{NiCl}_{2}$ (Sigma).

Histochemical processing of filled cells. At the end of recording, slices were fixed by immersion in $2.5 \%$ paraformaldehyde in $0.1 \mathrm{M}$ phosphate buffer, $\mathrm{pH} 7.4$, and were then processed after resectioning to $70 \mu \mathrm{m}$ or as whole mounts, using standard histochemical techniques (Horikawa and Armstrong, 1988). The biocytin-containing neurons were post-fixed with osmium, dehydrated, mounted on slides, and examined by light micros- copy. Only neurons that were located within the subthalamic nucleus were analyzed further (an example is shown in Fig. 1E).

Data analysis. Data were analyzed using Axograph 3.0 (Axon instruments), Kaleidagraph 3.08 (Synergy, Reading, PA), Statview 5.0 (SAS, Cary, NC), and Origin 5.0 (Microcal, Northampton, MA). Descriptive statistics refer to the mean \pm SD. Statistical comparisons were made using the Mann-Whitney $U$ test. Significance values of $p<0.05$ were considered significant.

\section{RESULTS}

\section{Subthalamic neurons are spontaneously active}

Subthalamic neurons exhibited slow and highly regular spontaneous activity in slices taken from the entire range of ages and under all other conditions tested. In a representative sample of 57 neurons, $42(74 \%)$ fired spontaneously. Some neurons ceased firing spontaneously over the course of several minutes of recording but could be induced to fire again by passage of small (10-100 pA) depolarizing currents. Spontaneous firing was robust in the neurons exhibiting the largest and briefest action potentials, showing the least change in membrane potential and input resistance over time, and capable of sustaining the highest rates of firing in response to current injection. Nonetheless, to determine whether spontaneous firing might somehow arise from damage caused by membrane rupture and intracellular dialysis associated with whole-cell recordings, spontaneous firing was assessed in 25 neurons recorded in the cell-attached mode before membrane rupture and compared with that seen afterward. All of these cells were spontaneously active and showed similar firing rates and patterns before and after establishment of whole-cell recording. An example is shown in Figure $1, A$ and $B$. A comparison of spontaneous firing at 25 and $35^{\circ} \mathrm{C}$ showed that the average frequency of spontaneous firing was approximately twice as fast at the higher temperature $\left(6.5 \pm 2.0 \mathrm{~Hz}\right.$ at $35^{\circ} \mathrm{C}, 3.6 \pm 1.0 \mathrm{~Hz}$ at $25^{\circ} \mathrm{C} ; n=10$ at each temperature). Temperature had no effect on the periodicity of the spontaneous firing, which was assessed using the coefficient of variation $\left(\mathrm{CV} ; 0.11 \pm 0.4\right.$ at $35^{\circ} \mathrm{C}, 0.12 \pm 0.06$ at $25^{\circ} \mathrm{C}$ ). These observations indicate that the pattern and rate of spontaneous firing seen in subthalamic neurons in whole-cell recordings is not an artifact of damage attributable to whole-cell recording. Spontaneous firing was also not dependent on the age of the animals from which slices were obtained. The subsequent results were obtained from animals between 18 and $27 \mathrm{~d}$, and there were no differences observed within that age range. The subsequent experiments were conducted at $25^{\circ} \mathrm{C}$.

The possibility that excitatory synaptic transmitter release acting within the slice might be responsible for spontaneous firing was examined by bath application of a combination of APV (50 $\mu \mathrm{M})$ and DNQX $(20 \mu \mathrm{M})$ to block excitatory amino acid neurotransmission. Five neurons studied before and after application of the glutamate antagonists showed no decrease in spontaneous firing (control, $2.5 \pm 0.7 \mathrm{~Hz}$; APV and DNQX, $3.0 \pm 0.6 \mathrm{~Hz}$ ). This treatment also had no effect on the periodicity of firing in these neurons (CV: control, $0.14+0.11$; APV and DNQX, 0.12 +0.08 ; Fig. $1 C, D)$.

\section{Sodium currents are essential for the oscillation}

In many neurons, slow spontaneous rhythmic firing like that of subthalamic neurons is driven by a subthreshold oscillation that does not depend on fast TTX-sensitive sodium action currents. In these neurons, hyperpolarization of the cell may not produce a continuous decrease in firing frequency but instead, near the threshold for action potential generation, a subthreshold oscilla- 
A CELL-ATTACHED

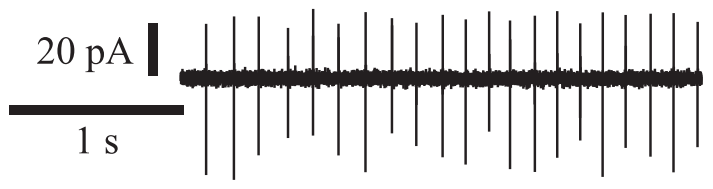

B

WHOLE-CELL

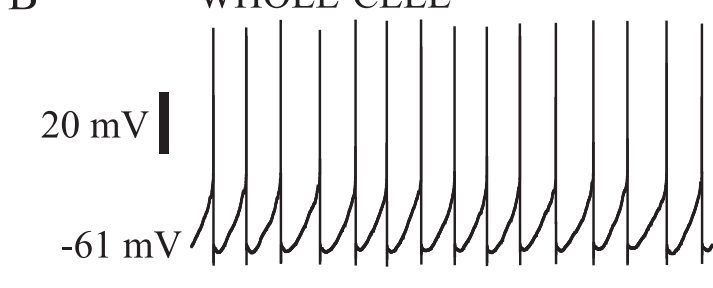

C

\section{CONTROL}

APV \& DNQX

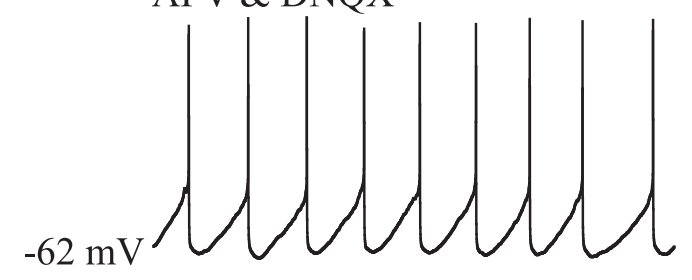

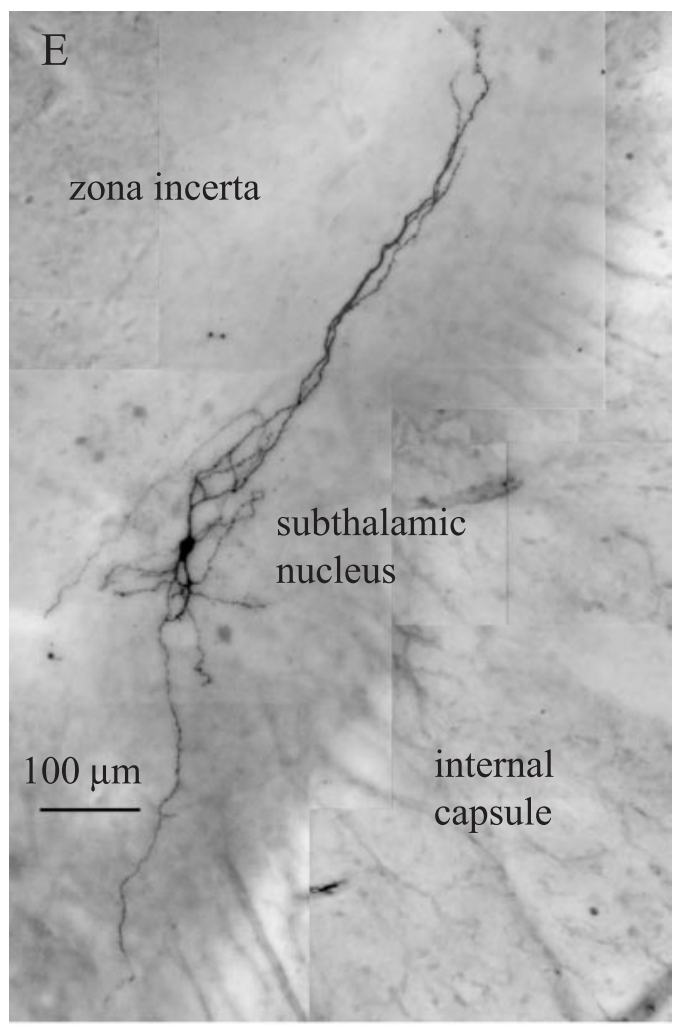

Figure 1. Subthalamic neurons were spontaneously active in vitro. $A, B$, Example of patch-clamp recordings from a subthalamic neuron that was recorded in the cell-attached configuration $(A)$ before establishing the whole-cell configuration $(B)$. Note the slow $(5-7 \mathrm{~Hz})$, rhythmic generation of action currents $(A)$ and action potentials $(B)$. $C, D$, Intrinsic membrane properties underlie the spontaneous discharge of subthalamic neurons in vitro. A spontaneously active subthalamic neuron $(C)$ continued to fire rhythmically when excitatory amino acid neurotransmission was blocked by the application of the selective NMDA and AMPA receptor antagonists APV and DNQX, respectively $(D)$. E, Composite image based on multiple light micrographs of a subthalamic neuron that was visualized using histochemical procedures (see Materials and Methods) after being recorded in the whole-cell configuration. Time calibration in $A$ applies to $A-D$. Current calibration in $A$ applies to that figure. Voltage calibration in $B$ applies to $B-D$. The membrane potential value printed at the left of each traces in this and all subsequent figures refers to the first point in the trace.

tion may be revealed on cycles in which no action potential occurs. In this case, the oscillation may alternate cycles, firing action potentials on one cycle and missing on others. Subthalamic neurons were examined for this mode of firing by gradually increasing their average membrane potentials with hyperpolarizing constant current. In the 10 neurons examined, firing remained rhythmic and decreased continuously in rate, with the cells firing at rates $<0.5 \mathrm{~Hz}$ before ceasing rhythmic spontaneous activity entirely. Subthreshold oscillations were never seen throughout the process and were not present on the membrane potential after firing stopped. An example is shown in Figure $2 A-C$. Similarly, the rhythmic variations in membrane potential depended absolutely on the integrity of TTX-sensitive sodium current. Bath application of TTX $(1 \mu \mathrm{M})$ in six neurons abolished spontaneous firing, leaving the neurons with stable resting membrane potentials with no sign of oscillation (Fig. $2 D-F$ ). Each neuron maintained membrane potentials within the range normally associated with rhythmic firing. Depolarization of these neurons to potentials within or beyond the level at which the spontaneous oscillations occurred never produced any subthreshold oscillation. Likewise, membrane potential oscillations could not be induced by release from long periods of artificial hyperpolarization.

\section{Hyperpolarization-activated sag current is not essential}

Subthalamic neurons showed a prominent slow hyperpolarizationactivated cation current that acts as a time-dependent inward rectifier at very negative membrane potentials (Fig. $3 A$ ). This current has been found important in spontaneous oscillations of thalamic and other neurons and so was examined for a possible role in the spontaneous rhythmic activity of subthalamic cells. In 10 neurons tested, application of currents that hyperpolarized the membrane to $-75 \mathrm{mV}$ or beyond was accompanied by clear sag in the response as expected for the hyperpolarization-activated current (Fig. 3A). This sag was blocked in a dose-dependent manner by addition of 1-5 mm cesium to the bath (Fig. $3 B$ ). Similarly, voltage steps from $-55 \mathrm{mV}$ to $-75 \mathrm{mV}$ and more negative potentials evoked a gradually increasing inward current in voltage-clamp experiments, which was likewise blocked in a dosedependent manner by cesium ( $n=5$; data not shown). Given that the peak amplitude of the afterhyperpolarization of 10 spontaneously firing neurons recorded using the fast current-clamp mode of the Axopatch 200B was $-65.7 \pm 4.0 \mathrm{mV}$ and the voltage sensitivity of the hyperpolarization-activated current, it is likely that this current is active in a voltage range more negative than 


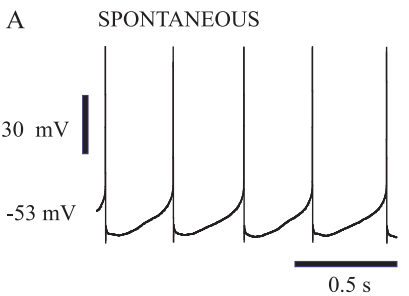

B $\quad-15 \mathrm{pA}$

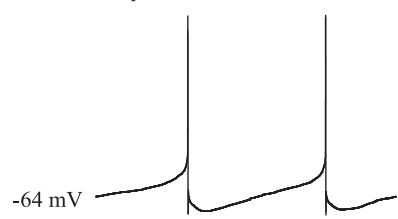

C $\quad-20 \mathrm{pA}$

$-66 \mathrm{mV} \ldots$
D

SPONTANEOUS

$-54 \mathrm{mV}$

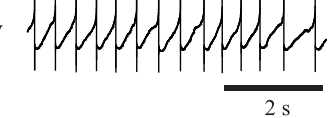

E

ONSET OF ACTION OF TTX

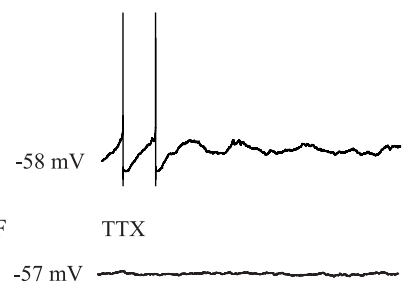

Figure 2. Sodium currents were critical to the spontaneous oscillation. Spontaneous oscillations of subthalamic neurons were abolished when action potential generation was prevented by the constant injection of negative current $(A-C)$. The injection of negative current to a spontaneously firing subthalamic neuron $(A)$ slowed rhythmic firing $(B)$ before preventing it $(C)$. When action potential generation was inhibited, underlying subthreshold oscillations were not observed $(C)$. The application of the sodium channel blocker TTX to a spontaneously active neuron $(D)$ abolished action potential generation $(E, F)$, which led to a stable membrane potential at the midpoint of the voltages traversed during the subthreshold phase of the oscillation $(F)$. Voltage calibration in $A$ applies to $A--F$. Time calibration in $A$ applies to $A--C$. Time calibration in $D$ applies to $D-F$.

A CONTROL

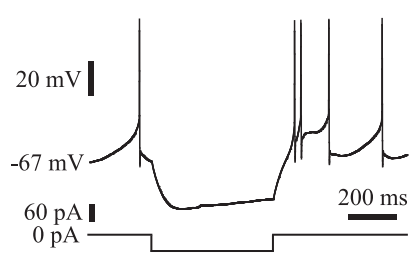

B

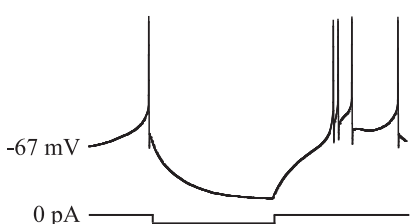

C CONTROL

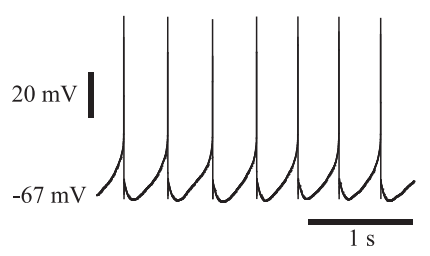

$\mathrm{D}$

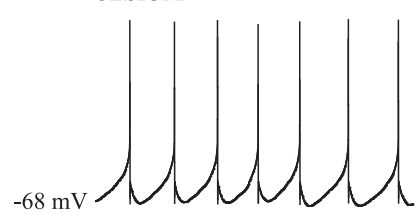

Figure 3. Hyperpolarization-activated sag current was not critical to the spontaneous oscillation. A subthalamic neuron responded to the injection of $-60 \mathrm{pA}$ for $500 \mathrm{msec}$ with a characteristic sag in membrane potential, which was attributable to the activation of hyperpolarization-activated sag current $(A)$. In the presence of $3 \mathrm{~mm}$ cesium hyperpolarization-activated sag current was blocked $(B)$. Despite the specific block of hyperpolarization-activated sag current, the spontaneous firing of the neuron in $3 \mathrm{~mm}$ cesium $(D)$ was similar to that observed in control ACSF $(C)$. Voltage, time, and current calibrations in $A$ also apply to $B$. Voltage and time calibrations in $C$ also apply to $D$.

that involved in the cycle of spontaneous firing. This expectation was supported by the absence of an effect of cesium (3-5 mM) on the spontaneous firing patterns of the cells (Fig. 3C,D). In eight neurons with an average spontaneous firing rate of $2.6 \pm 1.1 \mathrm{~Hz}$ and average interspike interval $\mathrm{CV}$ of $0.17 \pm 0.11$, the average firing rate was unchanged at $2.6 \pm 2.2$, and the average $\mathrm{CV}$ was $0.18 \pm 0.12$ after treatment with cesium.

\section{The oscillatory mechanism requires an apamin- sensitive calcium-dependent potassium current}

The large spike afterhyperpolarization, which limits firing to one action potential on each cycle of the oscillation, suggests the action of a powerful calcium-dependent potassium current. A general test for the involvement of calcium entry during spontaneous activity was performed in six neurons using blockade of high-voltage-activated (HVA) calcium currents with bath application of cadmium $(400 \mu \mathrm{M})$. In all cases, spike afterhyperpolarization was drastically reduced in depth and duration, and rhythmic spontaneous firing was disrupted. In two cells, cadmium treatment abolished spontaneous firing, and the cells established a stable resting potential within the range associated with rhythmic firing. In these cells, spiking could be restored by passage of small depolarizing currents. However, such firing was not rhythmic at rates comparable with that seen to occur spontaneously. Rhythmic firing in these cells could only be induced by depolarizations that produced higher-frequency ( $\geq 5 \mathrm{~Hz}$ ) firing. In the other neurons, spontaneous firing remained, increasing in rate in three cells and decreasing in one. In all of the cases in which spontaneous firing continued, there was a dramatic reduction in the regularity of firing, with $\mathrm{CV}$ of interspike intervals increasing from 2.4- to 6.9-fold over that seen before cadmium treatment. In two cases, the $\mathrm{CV}$ increased to be $>1$, indicating a dramatic irregularity of spontaneous firing. Both the loss of rhythmicity in the spontaneous firing and the reduction in the spike afterhyperpolarization are illustrated in the example in Figure 4, $A$ and $B$.

Because calcium entry may promote spike afterhyperpolarization by a variety of means, we tested the effect of apamin (100 $\mathrm{nM}$ ), a specific antagonist of the small-conductance calciumdependent potassium channel $\left(\mathrm{SK}_{\mathrm{Ca}}\right)$, in five neurons and compared its effects with those of cadmium. Apamin treatment, like blockade of calcium currents, produced a disruption of spike afterhyperpolarization and rhythmic spontaneous firing. Although all the cells treated with apamin continued to fire spontaneously, the periodicity of the firing was dramatically reduced in four of five cells, as indicated by an increase in CV from 1.7- to 11 -fold. In the other neuron, the firing rate increased dramatically, and the cell continued to fire rhythmically at the higher firing rate. As with cadmium, apamin disrupted rhythmic firing only at low rates of activity comparable with those seen spontaneously. Rhythmic firing was still observed at higher $(\geq 5 \mathrm{~Hz})$ firing rates. An example showing the effect of apamin treatment on spike afterhyperpolarization and on spontaneous firing is shown in Figure 4, $C$ and $D$.

\section{The depolarizing phase is caused by a persistent sodium current}

These experiments suggest that the slow spontaneous rhythmic firing of subthalamic neurons is generated by the depolarizing effect of a sodium current active at the equilibrium point of the membrane in the resting range and the powerful calciumdependent potassium currents that are elicited by the single action potential that occurs at the peak of the depolarizing phase of the oscillation. This view is consistent with the absence of persistent depolarizing potentials in the resting voltage range recorded at the end of $500 \mathrm{msec}$ current steps in TTX-treated neurons (Fig. 5A). The sodium current responsible for the depolarizing phase of the oscillation is unlikely to be rapidly inactivating, because of the long-duration of the ramp and its ability to sustain rhythmic firing at very low rates. This view of the oscillation predicts that in the absence of spike-generated potassium 
A

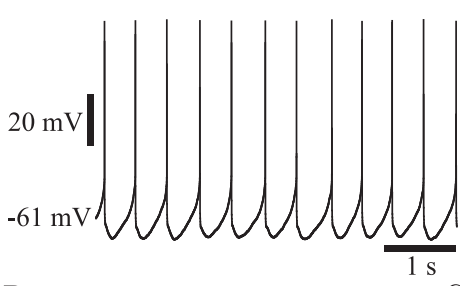

B

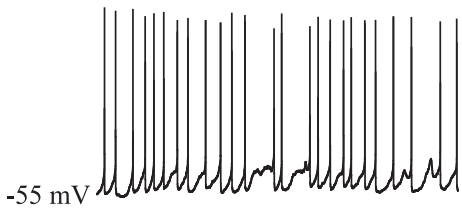

C

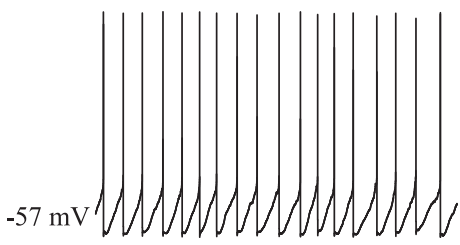

CONTROL
CONTROL

CADMIUM
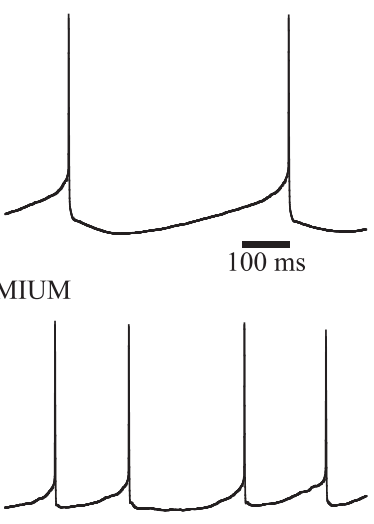
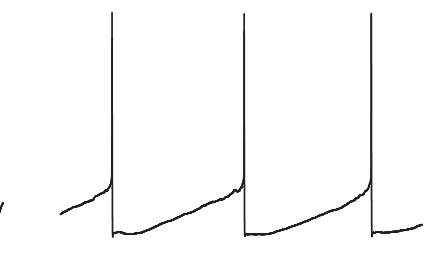

APAMIN
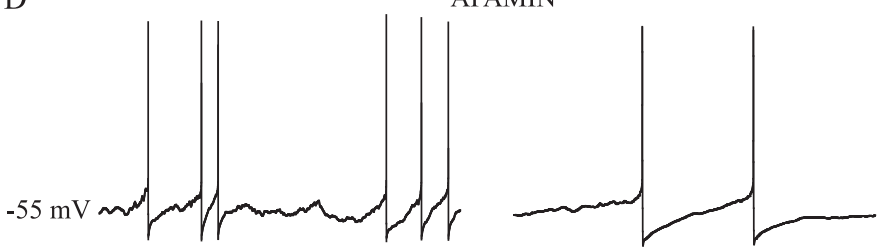

Figure 4. High-voltage-activated calcium currents activated potassium currents that underlie the slow single-spike afterhyperpolarization of the spontaneous oscillation. The rhythmic, spontaneous firing of subthalamic neurons $(A, C)$ was disrupted by the application of HVA calcium current blocker (400 $\mu \mathrm{m}$ cadmium; $B$ ) or $\mathrm{SK}_{\mathrm{Ca}}$ current blocker (100 nM apamin; $D)$. High-voltage-activated and $\mathrm{SK}_{\mathrm{Ca}}$ current blockade disrupted rhythmic firing by abolishing the slow single-spike afterhyperpolarization, which was activated within a few milliseconds of spike repolarization and lasted for tens or hundreds of milliseconds before the depolarizing ramp current was activated. Voltage and time calibrations in $A$ apply to the respective parts of $B$ and $C$.

currents, the whole neuron $I-V$ curve would exhibit a net negative slope conductance over the voltage range seen during depolarizing phase of the oscillation ( -60 to $-45 \mathrm{mV}$ ), and the negative slope conductance should be abolished by TTX application. We tested this hypothesis in five neurons recorded in voltage-clamp mode using $1 \mathrm{sec}$ voltage steps from $-65 \mathrm{mV}$ to potentials ranging from -90 to $-25 \mathrm{mV}$. Series resistance in these recordings ranged from 7 to $20 \mathrm{M} \Omega$ and was not compensated electrically at the time of the experiment. Because the currents were small $(<250 \mathrm{pA})$, the resulting voltage error was always $<5 \mathrm{mV}$ and was $<2.5 \mathrm{mV}$ over the voltage range associated with the oscillation. Current was measured at the end of a $1 \mathrm{sec}$ pulse, at which time most of the transients had settled. The results of these experiments are shown in Figure $5 B-D$. In control media, cells showed no zero current point in the subthreshold range, and the entire voltage range associated with the depolarizing phase of the oscillation ( -60 to $-45 \mathrm{mV}$ ) fell within the range of negative slope conductance. Treatment with TTX abolished this range. The voltage sensitivity of TTX-sensitive inward current responsible for the negative slope conductance was estimated by subtracting the $I-V$ curve obtained after TTX from the control curve. The

difference current for the entire sample is shown in Figure $5 D$. The current activated between -60 and $-45 \mathrm{mV}$ and decreased in amplitude beyond $-45 \mathrm{mV}$. At $-25 \mathrm{mV}$, well short of the reversal potential for sodium, it appears to be entirely gone. Although this may suggest that the negative slope region in the steady-state $I-V$ curve is attributable to a window current, this apparent reduction in the TTX-sensitive current may also result from outward currents generated by potassium channels in poorly controlled regions of the dendrites. Dendritic sodium currents activated by the voltage pulses could produce larger depolarizations in poorly controlled parts of the dendrites than are achieved in the soma. These could contribute to the inward current seen in the soma. Likewise, potassium currents in the dendrites may act to counteract the inward currents seen at the soma. We attempted to block such dendritic potassium currents by application of TEA (5 mM) and repeated the voltage-clamp experiments. When potassium channels were blocked, voltage steps beyond $-45 \mathrm{mV}$ produced uncontrolled spiking, presumably in the dendrites. For steps to $-45 \mathrm{mV}$ and more negative, the results were similar to those in control media (Fig. $5 E, F$ ). Thus, it cannot be determined from the $I-V$ curve shown in Figure $5 D$ whether the steady-state sodium conductance responsible for the negative slope region is inactivating beyond $-45 \mathrm{mV}$ or whether the apparent decrease in current is attributable to recruitment of dendritic potassium currents superimposed on a noninactivating sodium current.

\section{Calcium currents are activated primarily by action potentials}

Although the negative slope conductance region and spontaneous membrane potential oscillation did not survive treatment with TTX, it is possible that a TTX-insensitive calcium conductance contributes to the inward currents during the oscillation but is not sufficient to maintain them by itself. The presence of such a conductance was tested by comparing the steady-state current in the presence of TTX and TEA before and after the addition of cadmium $(400 \mu \mathrm{M})$ to block calcium currents (Fig. 5G,H). The results of this are shown for the entire sample $(n=5)$ in Figure $5 H$. Addition of cadmium blocked a constant small inward current ( $\sim 10 \mathrm{pA}$ on average) that was present even at very hyperpolarized potentials. In addition, there was a larger but more variable inward current that was activated in the membrane potential range associated with the oscillations. This cadmium-sensitive inward current peaked above threshold and was much smaller and more variable than the sodium current. Thus there is a steadystate calcium current contributing to the depolarization phase of the oscillation but small in comparison with the sodium current.

A possible role for inactivating low-voltage-activated (LVA) calcium current, which would not be evident in our steady-state $I-V$ curves, was tested by examination of the voltage-clamp records used to generate Figure $5 \mathrm{C}-\mathrm{H}$. These showed no prominent inactivating calcium current (either cadmium-sensitive or -insensitive) associated with steps from -65 to $-45 \mathrm{mV}$ (the relevant range for the oscillations). Such inactivating inward calcium currents were seen when voltage steps to $-55 \mathrm{mV}$ were made from $-70 \mathrm{mV}(-19.8 \pm 26.8 \mathrm{pA} ; n=5)$ and peaked when voltage steps were made from $-95 \mathrm{mV}(-161.2 \pm 81.3 \mathrm{pA} ; n=$ 5). Likewise, in current-clamp experiments, a rebound depolarizing potential was only observed with release of currents that held the membrane below approximately $-70 \mathrm{mV}(n=10)$. Finally, in five neurons tested with $100 \mu \mathrm{M}$ nickel (which is an antagonist of LVA calcium currents in many cells), rebound responses from release of strong hyperpolarizations were clearly 
A

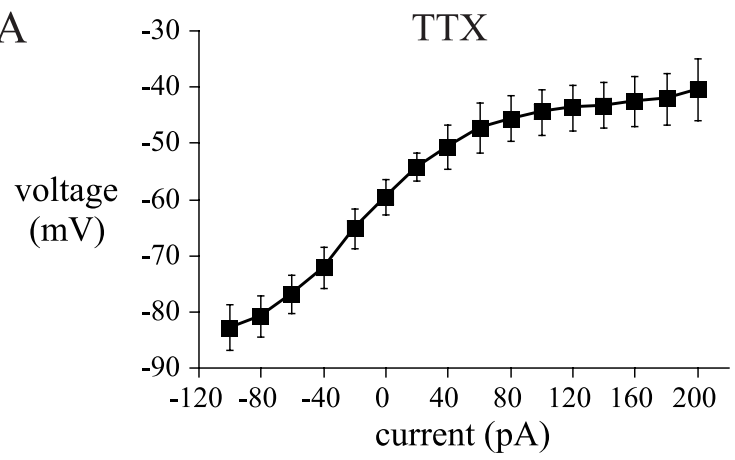

B

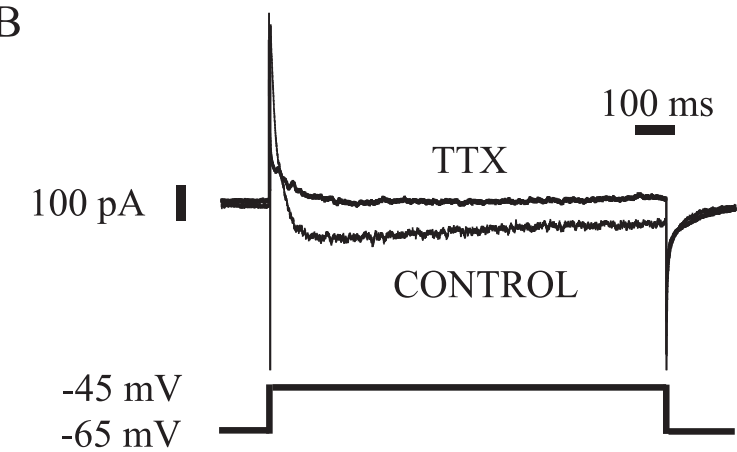

C
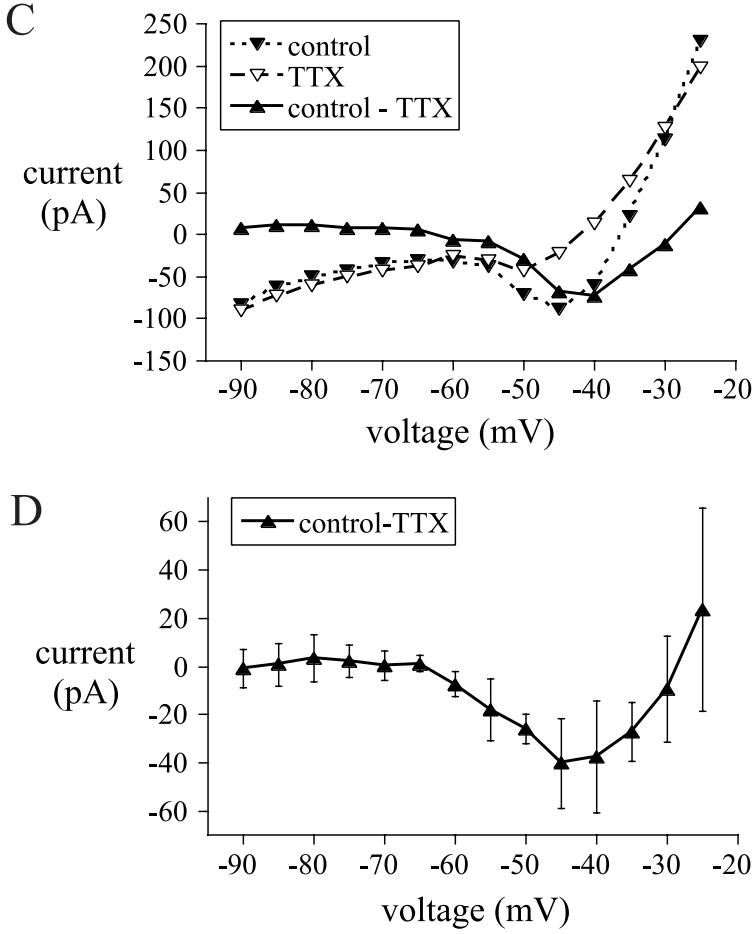

E

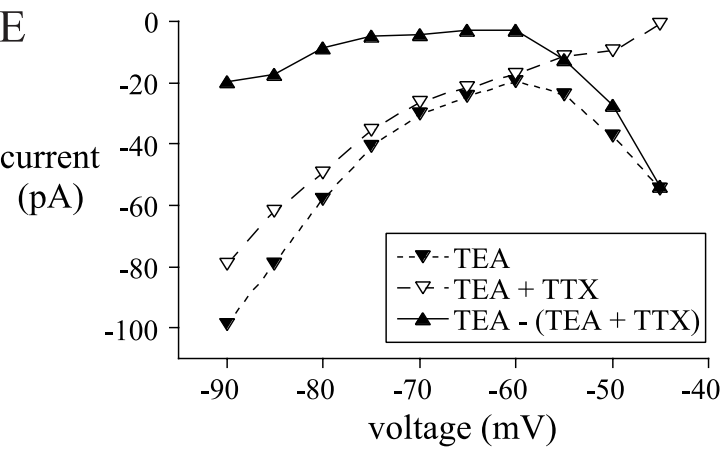

F

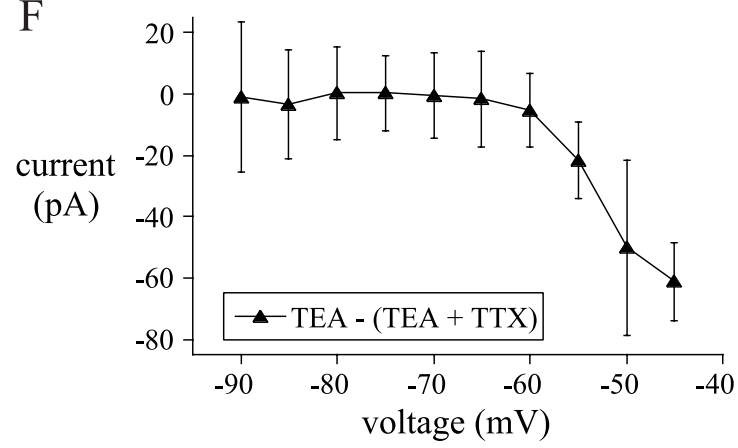

G

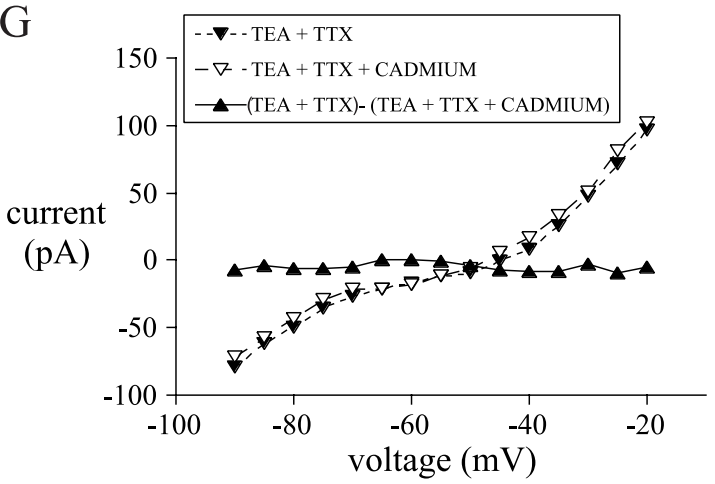

H

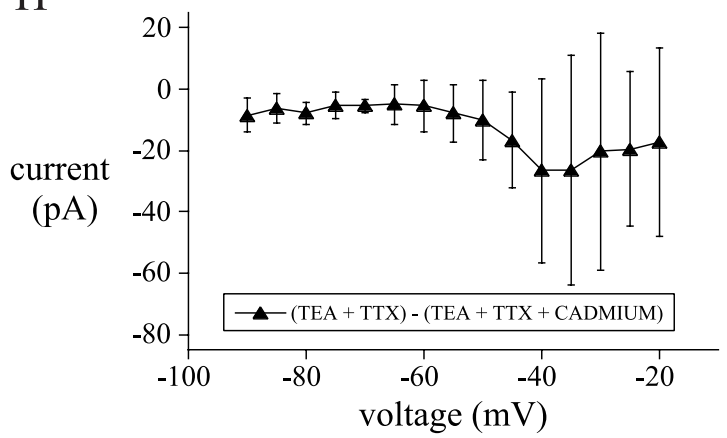

Figure 5. A persistent sodium current was responsible for the depolarizing phase of the spontaneous oscillation. $A$, Steady-state $I-V$ plot of eight subthalamic neurons recorded in current clamp in the presence of the sodium channel blocker TTX revealed no depolarizing potential in the subthreshold range of the oscillation. Inward and outward rectification were apparent at hyperpolarized and depolarized potentials, respectively. Voltage-clamp recordings were used to examine persistent currents that might underlie the depolarizing phase of the oscillation. $B$, A persistent TTX-sensitive current was elicited by a $1 \mathrm{sec}$ step from -65 to $-45 \mathrm{mV}$. $C$, Steady-state $I-V$ plot of currents elicited from the same neuron in $B$ at the end of $1 \mathrm{sec}$ steps from holding of $-65 \mathrm{mV}$. Note that in control media an inward current was activated in the voltage range associated with the depolarizing phase of the spontaneous oscillation. The inward current was abolished in TTX. The TTX-sensitive sodium current (current in control media - current in TTX) shows similar voltage dependency and magnitude to the inward current observed in control media. $D$, The $I-V$ plot of the persistent sodium current recorded from a population of five neurons using the same protocol exhibited a similar voltage dependence to the current in $C$. $E-H, I-V$ plots of currents elicited at the end of $1 \mathrm{sec}$ steps from holding potential of $-55 \mathrm{mV}$ from a representative neuron $(E, G)$ and from a sample of five neurons $(F, H)$. Steps were made in the presence of TEA, TEA, and TTX and TEA, TTX, and cadmium. Sodium (TTX-sensitive) current was obtained by subtraction of currents in TEA and TTX from currents in TEA. High-voltage-activated calcium (cadmium-sensitive) current was obtained by subtraction of currents in TEA and TTX from TEA, TTX, and cadmium. Note that the persistent sodium current is activated in the subthreshold range of the oscillation $(E, F)$, whereas persistent calcium currents are smaller and less reliable in the subthreshold range $(G$ - $H)$. 
reduced, but spontaneous rhythmic single spiking was not significantly altered in frequency or rhythmicity. Mean firing rate before and after nickel treatment ranged from 1.7 to $3.5 \mathrm{~Hz}$ (mean, 2.5; SD, 0.72) and from 1.7 to $4.8 \mathrm{~Hz}$ (mean, 3.4; SD, 1.3), respectively. The $\mathrm{CV}$ for interspike intervals was not altered by nickel treatment (control mean, $0.09 \pm 0.04$; nickel mean, $0.10 \pm$ 0.03 ). Thus the disruption of the oscillation seen after cadmium treatment is attributable almost entirely to the reduction in calcium-dependent potassium currents in the spike afterhyperpolarization, but the calcium entry is primarily triggered by the spike rather than the depolarizing ramp of the oscillation.

\section{Driven firing pattern of subthalamic neurons}

Although their spontaneous rhythmic firing was slow, subthalamic neurons were capable of firing at rates as high as several hundred hertz in response to synaptic input or current injections (Fig. 6). The relationship between the mechanism of the slow spontaneous rhythmic firing and the high-frequency firing during imposed depolarizations was studied using the response to current injections of $500 \mathrm{msec}$ duration during whole-cell recording.

The response of subthalamic neurons to current injections is illustrated in Figure 6. The driven activity of the neurons showed a very wide dynamic range, achieving firing rates as high as $300-500 \mathrm{~Hz}$, and continued to increase their firing rates with currents as high as $1000 \mathrm{pA}$. Despite the passage of such large currents, the membrane potential between action potentials traversed approximately the same voltage range seen during spontaneous firing. At very high currents, repetitive firing failed when the membrane potential failed to repolarize back into the negative slope conductance region of the membrane potential and was replaced by a constant depolarized plateau. The frequencycurrent $(f-I)$ curve was sigmoidal in shape, with small increments in frequency achieved with incremental increases in current up to a firing rate of about $\sim \mathrm{Hz}$, after which the frequency increased much more rapidly with increases in current (the gradient of the $f-I$ relationship of the secondary range was $\sim 1.9 \pm 0.4$-fold greater than that of the primary range; $n=22$ ). Near the maximal firing rate the slope of the $f-I$ curve was again reduced (tertiary range). Except at the lowest firing rates, subthalamic neurons showed an initial increase in firing rate over the first few action potentials during driven repetitive firing (Fig. 6). This initial increase in firing rate was followed by a relatively small but very reliable spike frequency adaptation (Fig. 6). Application of cadmium (400 $\mu \mathrm{M} ; n=5)$ to the bath increased the minimum rate of repetitive firing, and increased the slope of the primary $f-I$ curve (2.4 \pm 2.1 -fold; $n=3$ ) or abolished it completely $(n=2)$ (Fig. $6 C)$. Application of apamin $(100 \mathrm{nM} ; n=5)$ had similar effects. It increased the minimum rate of repetitive firing, and increased the slope of the primary $f-I$ curve $(1.5 \pm 0.3$-fold; $n=3)$ or abolished it completely $(n=2)$. The current required to obtain firing at the maximal rate was reduced (Fig. 6D). In summary, after apamin or cadmium treatment, the sigmoidal shape of the $f-I$ curve was lost and was replaced by an initially linear relationship with a slope resembling the highest slope region of the sigmoidal curve.

The sigmoidal shape of the $f-I$ relationship could arise from either the activation of an inward current during high-frequency firing or saturation of calcium- or sodium-dependent potassium current that limits firing rate at low current levels. To test for saturation of the calcium-dependent potassium current, we measured the duration of the afterhyperpolarization following a 500 msec period of high-frequency firing evoked by current pulses in four spontaneously firing neurons. The duration of the afterhy- perpolarization was estimated from the latency to the first spontaneous action potential after the termination of the current pulse. The results are shown for a representative neuron in Figure 7. Afterhyperpolarization increased smoothly with firing rate during the pulse, with no indication of any reduction in the accumulation of afterhyperpolarization associated with the onset of the high slope region near firing rates of $35 \mathrm{~Hz}$. Even at the highest rates tested, afterhyperpolarization continued to increase with increases in the firing rate during the pulse. These results indicate saturation of the calcium- or sodium-dependent potassium current could not explain the sigmoidal shape of the $f-I$ curve.

\section{DISCUSSION}

\section{Slow rhythmic firing is the resting state of subthalamic neurons}

In slices, subthalamic neurons exhibited slow rhythmic firing that was not disrupted by blockade of fast excitatory amino acid neurotransmitter receptors. This observation rules out recurrent excitatory connections within the subthalamic nucleus, although such connections have been demonstrated (Hammond and Yelnik, 1983; Kita et al., 1983), or action potential-independent synaptic activity at glutamatergic intrinsic or afferent synapses as an explanation for the observed patterns of activity. Moreover, analysis of the intrinsic properties showed that the cells exhibit a negative slope conductance over the membrane potential range associated with rest and have no stable resting membrane potential subthreshold for action potential generation. Spontaneous oscillation was observed in animals over a range of ages between postnatal weeks 3 and 4 and is consistent with the activity reported for subthalamic neurons in adult animals (DeLong et al., 1985; Yung et al., 1991; Matsumara et al., 1992; Fujimoto and Kita, 1993; Wichmann et al., 1994; Overton and Greenfield, 1995), although it has not previously been shown to be independent of synaptic input. We conclude that in the absence of input, the neurons are engaged in a stable oscillation, and synaptic inputs to the subthalamic neurons interact with this rhythm to generate the output of the nucleus (Calvin and Stevens, 1967, 1968; Hausser and Clark, 1997; Bennett and Wilson, 1998). Conceptualization of synaptic integration in these neurons based on linear or nearly linear summation of synaptic potentials is not likely to yield accurate results.

\section{Mechanisms underlying the subthalamic neuron oscillation}

The cycle of the resting oscillation of subthalamic neurons consisted of single action potential, followed immediately by a powerful and long-duration afterhyperpolarization, and a subsequent slow-ramp depolarization that led to firing of a single spike.

The occurrence of only one action potential on each cycle and the immediate and powerful spike afterhyperpolarization suggested that the oscillation depended critically on the occurrence of full action potentials. Inhibition of action potential generation by injection of hyperpolarizing current or TTX treatment unconditionally abolished the slow rhythmic membrane potential oscillations, indicating that voltage-dependent sodium currents were essential to the oscillatory mechanism. Thus, subthalamic neurons do not belong to the class of neurons that support stable rhythmic oscillatory activity based on inward subthreshold calcium currents (e.g., Shepard and Bunney, 1991; Kang and Kitai, 1993). The low frequency of the oscillation suggests that the 
A

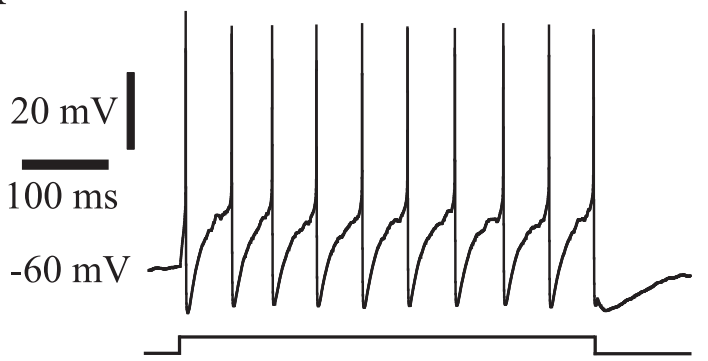

$-57 \mathrm{mV}$

$300 \mathrm{pA}$

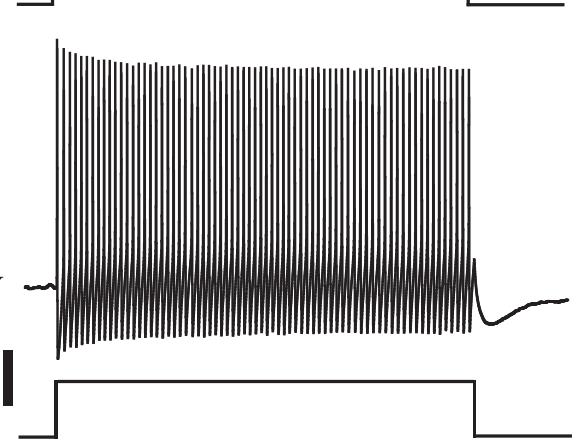

B

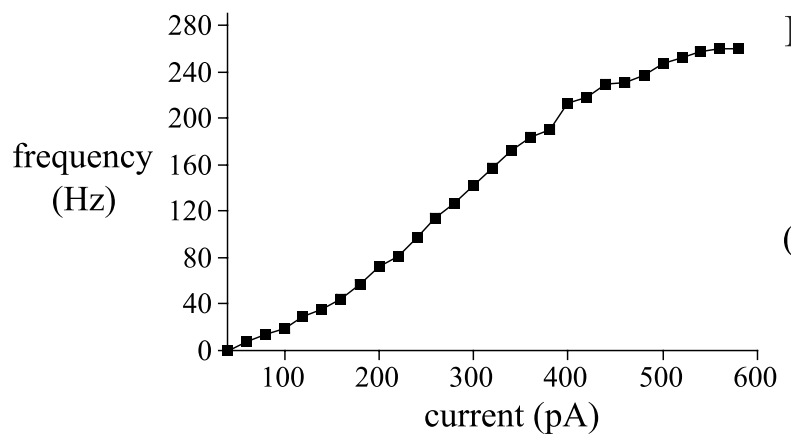

C
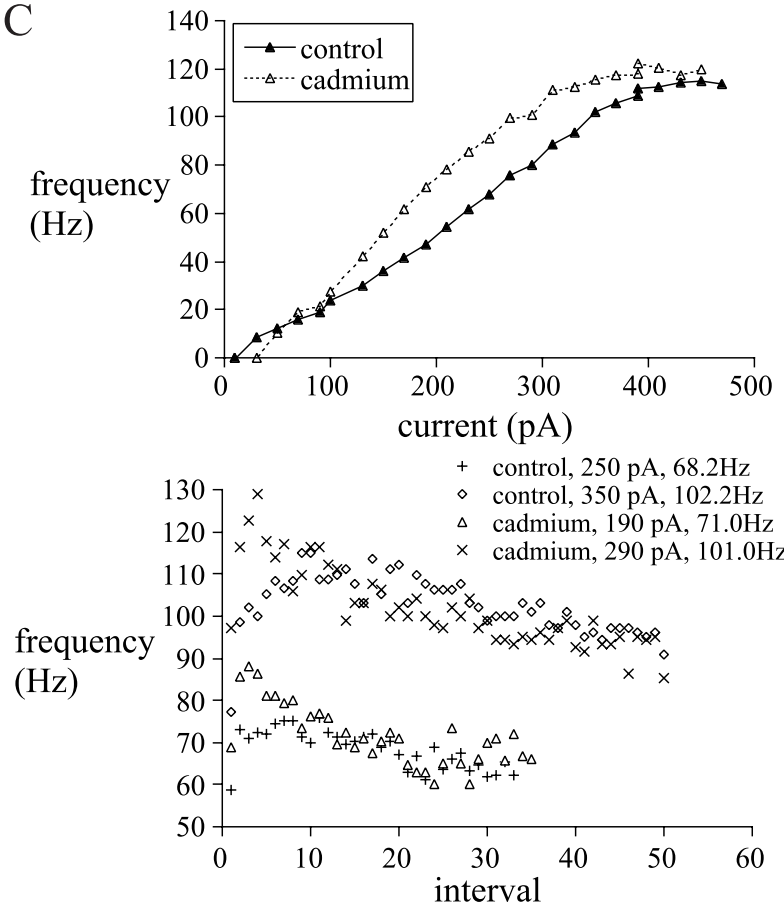

$\mathrm{D}$
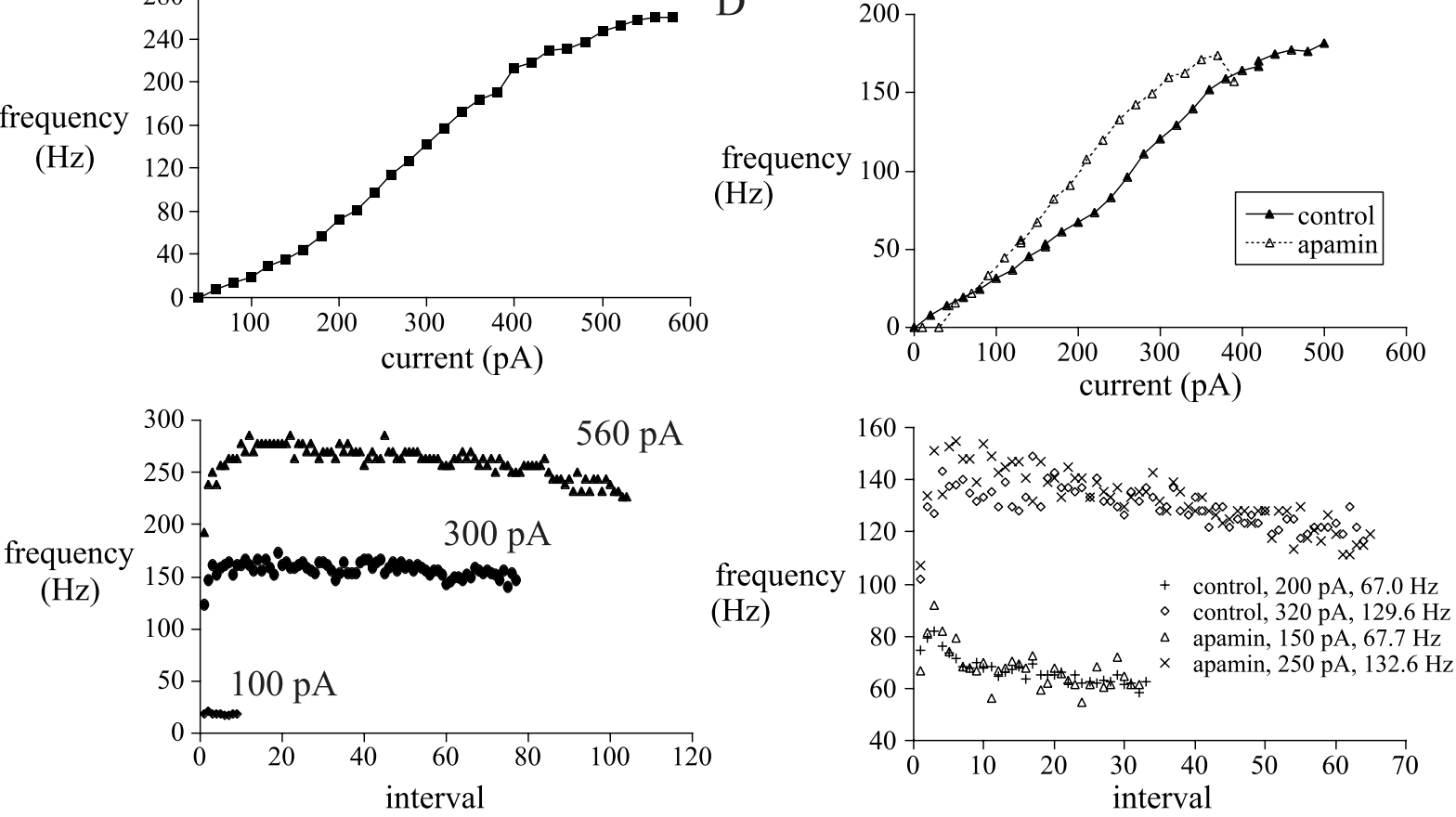

Figure 6. Subthalamic neurons fired rhythmically with minimal spike frequency adaptation in response to current injection and exhibited a sigmoidal $f-I$ relationship. $A$, Example of driven rhythmic firing by a subthalamic neuron. $B$, The same neuron displayed a sigmoidal $f-I$ relationship. Note the transition to secondary range firing occurred at $\sim 35 \mathrm{~Hz}$. Subthalamic neurons exhibited a rapid speed-up in instantaneous firing frequency in the first few intervals of a driven spike train in the secondary and tertiary ranges. From the point of maximal firing frequency a small spike frequency adaptation developed slowly. $C, D$, Calcium-activated potassium current limited excitability of subthalamic neurons during high-frequency firing. Suppression of calcium-activated potassium currents with cadmium $(C)$ or apamin $(D)$ shifted the $f-I$ relationship to the left and disrupted low-frequency firing associated with the primary range. Speed-up and spike frequency adaptation within driven trains of spikes were present when calcium and $\mathrm{SK}_{\mathrm{Ca}}$ currents were blocked.

depolarizing phase of the oscillation is not caused by rapidly inactivating currents. Hyperpolarization-activated cationic current and LVA calcium currents were not important in determining the rate or rhythmicity of spontaneous firing, apparently because their voltage ranges of activation and recovery from inactivation, respectively, were not traversed during this activity. However, the depolarizing phase of the oscillation was abolished by TTX treatment, and both current- and voltage-clamp recordings in the presence of TTX did not reveal an inward current (or a slowly inactivating outward current) that could account for the depolarizing phase. Steady-state $I-V$ curves generated in control media using whole-cell voltage clamp revealed a negative slope conductance in the subthreshold voltage range, which was abolished by the application of TTX. This regenerative process is 

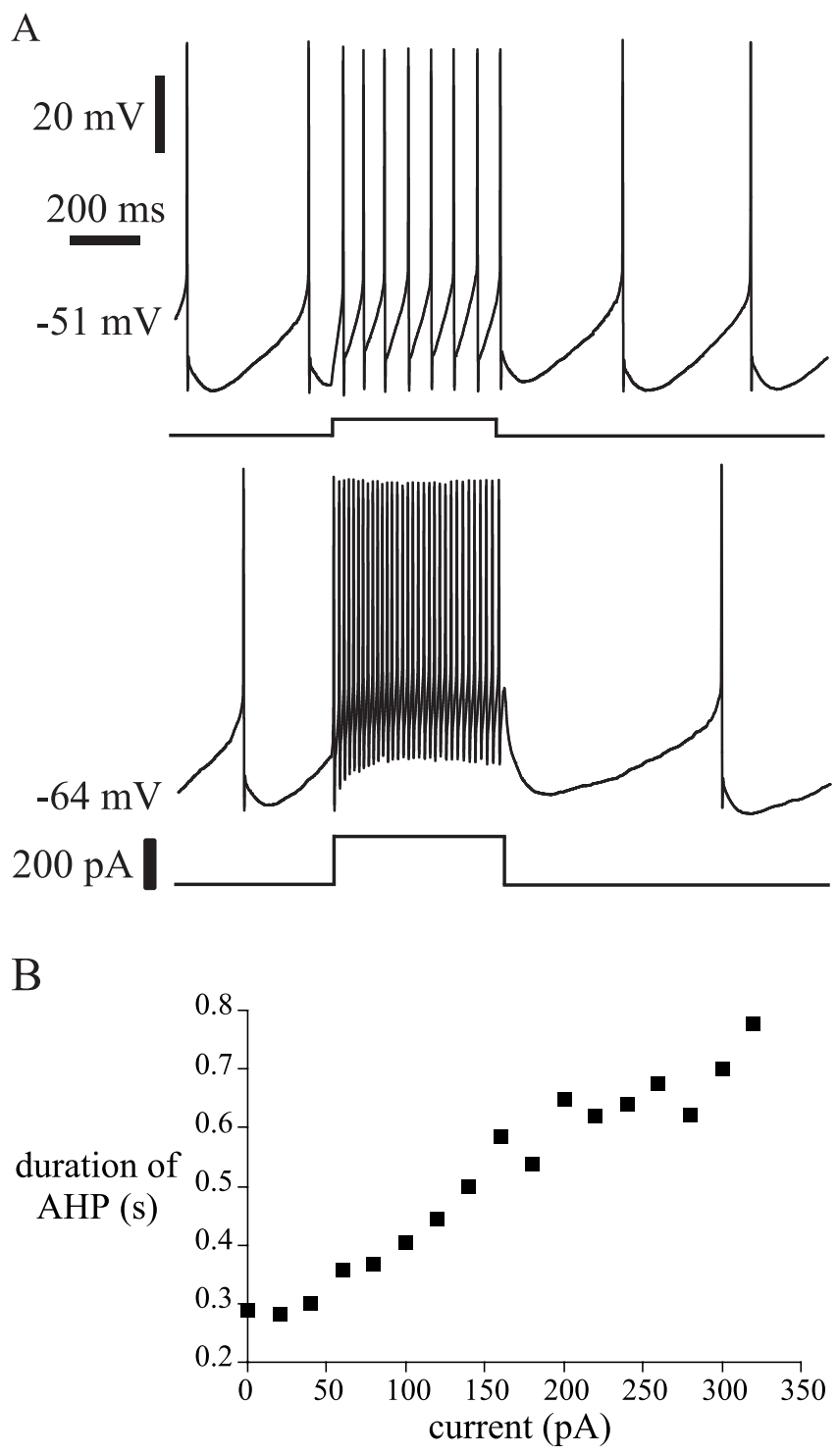

Figure 7. Saturation of afterhyperpolarization did not account for the sigmoidal $f-I$ relationship of subthalamic neurons because afterhyperpolarization accumulated during high-frequency firing. $A$, $B$, Representative example of a spontaneously firing subthalamic neuron, which was injected with an increasing magnitude of current. Note that the time to the resumption of spontaneous firing, a measure of afterhyperpolarization, increased as both elicited firing frequency and driving current increased.

sufficient for generation of the ramp depolarization and is caused by the activation of a persistent TTX-sensitive inward current. The characteristics of the channels responsible for this current cannot be determined from our experiments (but for some possibilities see Stafstrom et al., 1982, 1985; Alzheimer et al., 1993; Crill, 1996; Fleidervish and Gutnick, 1996; Fleidervish et al., 1996; Raman and Bean, 1997, 1999; Cummins et al., 1998; Kay et al., 1998; Parri and Crunelli, 1998). Its apparent steady-state voltage sensitivity was suggestive of a window current, but this could not be relied on because of almost certain contamination by voltage-sensitive potassium currents and possibly also uncontrolled inward currents in the dendrites (White et al., 1995).

Whereas calcium currents were not necessary or sufficient for generation of the depolarizing phase of the action potential, they were essential for the hyperpolarizing phase of the oscillation.
Low-frequency rhythmic firing was abolished by HVA calcium current blockade with cadmium. Cadmium, which at micromolar concentration acts as a broad-spectrum HVA calcium channel blocker, disrupted rhythmic spontaneous activity by altering the afterhyperpolarization that followed each action potential. The interspike interval in control media was characterized by a fast afterhyperpolarization, followed by a much longer-lasting one, which primarily determined the period of the oscillation. In cadmium, the slower afterhyperpolarization was abolished with little or no effect on the faster one. Blockade of $\mathrm{SK}_{\mathrm{Ca}}$ current with apamin disrupted spontaneous activity in a manner similar to the blockade of HVA calcium current by abolishing the slow component of the single spike afterhyperpolarization. The effects of cadmium and apamin on the spike afterhyperpolarization were the same for all cells, but some cells quit firing spontaneously, whereas some fired faster. In all cells, the minimum firing rate for spontaneous activity was increased. These results are all consistent with a reduction in spike afterhyperpolarization. When the strength and duration of the afterhyperpolarization is reduced, cells must either increase firing rate to remain above the minimum rate at which spontaneous rhythmic activity is supported by the shorter afterhyperpolarization or must quit firing rhythmically. If the net effect of all other currents places the cell well within the range of the persistent sodium current, it should speed up to maintain rhythmic firing. If not, the cell should find a stable resting membrane potential below the threshold for the sodium current. In either case, rhythmic activity was not observed at the low rates normally seen spontaneously. The slow component of the single-spike afterhyperpolarization in subthalamic neurons was similar in duration and apamin sensitivity to the medium afterhyperpolarization observed in cortical pyramidal cells and elsewhere (Blatz and Magleby, 1987; Schwindt et al., 1988a; Sanchez and Ribas, 1991; Lorenzon and Foehring, 1992; Pineda et al., 1992, 1998; Sah, 1992, 1996; Sah and McLachlan, 1992; Viana et al., 1993; Zhang and McBain, 1995; Gorelova and Reiner, 1996; Marrion and Tavalin, 1998; Vergara et al., 1998). Several studies suggest that the medium afterhyperpolarization is activated within 1-5 msec of the action potential and decays with a time constant of a few hundred milliseconds. These voltageindependent $\mathrm{SK}_{\mathrm{Ca}}$ channels are sensitive to nanomolar concentrations of intracellular calcium and have therefore been proposed to set the overall level of neuronal excitability by sensing average free intracellular calcium concentration (Blatz and Magleby, 1987; Sah, 1996; Vergara et al., 1998). $I-V$ plots in the presence of TTX revealed no depolarizing potential in the pacemaker voltage range, and whole-cell steady-state HVA current was barely apparent at subthreshold voltages. These data indicate that the major calcium flux during spontaneous firing occurs during the action potential and that its major contribution is the activation of the slow component of the single-spike afterhyperpolarization. This interpretation is consistent with the observation that subthalamic neurons cannot support subthreshold oscillations. A similar role for HVA calcium current in spontaneous firing has been described in other neurons (Paton et al., 1991; Pennartz et al., 1997; Raman and Bean, 1999).

\section{Subthalamic neurons have a sigmoidal $f-I$ relationship}

Plots of steady-state firing frequency against magnitude of injected current revealed that subthalamic neurons possess a sigmoidal $f-I$ relationship consisting of a low-sensitivity primary range up to $\sim 40 \mathrm{~Hz}$, a more sensitive secondary range, and a tertiary range in which firing level saturates. Sigmoidal $f-I$ rela- 
tionships have also been described in spinal motoneurons (Kernell and Sjoholm, 1973; Schwindt, 1973; Schwindt and Calvin, 1973; Mauritz et al., 1974; Heyer and Llinas, 1977; Schwindt and Crill, 1977, 1980, 1982). The majority of central neurons possess just two ranges: a linear primary range and a secondary range associated with the saturation of firing (MacGregor and Sharpless, 1973; Schwartzkroin, 1978; Stafstrom et al., 1984). Blockade of HVA calcium currents and calcium-activated potassium shifted the $f-I$ relationship to the left, consistent with the view that at high frequencies, $\mathrm{SK}_{\mathrm{Ca}}$ current contributes to the overall level of excitability (Blatz and Magleby, 1987; Schwindt et al., 1988a; Sanchez and Ribas, 1991; Lorenzon and Foehring, 1992; Pineda et al., 1992, 1998; Sah, 1992, 1996; Sah and McLachlan, 1992; Viana et al., 1993; Zhang and McBain, 1995; Gorelova and Reiner, 1996; Marrion and Tavalin, 1998; Vergara et al., 1998). The slow afterhyperpolarization that follows a driven train of spikes was found to accumulate smoothly in the primary and secondary ranges, suggesting that the transition to secondary range firing cannot be accounted for by the saturation of calciumor sodium-activated potassium currents, which have also been demonstrated to limit excitability for long periods in many other neurons (Schwindt et al., 1988a,b, 1989; Foehring et al., 1989; Lorenzon and Foehring, 1992; Sah, 1993, 1996; Greffath et al., 1998; Kim and McCormick, 1998; Pineda et al., 1998; Tanabe et al., 1998; Vergara et al., 1998). Because the average of the membrane potential trajectory during high-frequency firing moves more deeply into the negative slope region of the steadystate $I-V$ curve, we suggest that the persistent sodium current is responsible for the enhanced sensitivity in the secondary firing range. This explanation is similar to one used to account for the secondary range of spinal motorneurons and was based on studies of membrane potential trajectory between spikes, modeling studies, and the demonstration of a persistent inward current that was increasingly activated at voltages associated with secondary range firing (Kernell and Sjoholm, 1973; MacGregor and Sharpless, 1973; Schwindt, 1973; Schwindt and Calvin, 1973; Mauritz et al., 1974; Heyer and Llinas, 1977; Schwindt and Crill, 1977, 1980, 1982; Calvin, 1978). This explanation may also account for the speed-up of firing seen at the onset of high-frequency trains in subthalamic neurons. Over the first few cycles of high-frequency firing, the average membrane potential consistently increased, which may produce a greater sustained contribution of sodium current. An alternative possibility is a persistent HVA calcium current, which is not coupled to the medium afterhyperpolarization or slow afterhyperpolarization and is recruited as membrane potential increasingly traverses suprathreshold levels during highfrequency activity (Schwindt and Crill, 1977, 1982; Viana et al., 1993; Beurrier et al., 1999). Our experiments failed to reveal calcium currents activated over the subthreshold range of membrane potentials, but currents activated during the action potentials could contribute to depolarization in the interspike interval if not matched by increased afterhyperpolarization.

\section{Functional implications}

Subthalamic neurons drive the inhibitory output of the basal ganglia in resting animals, and interruption of subthalamic activity and therefore basal ganglia output generates uncontrolled involuntary movement (DeLong et al., 1985; Nakanishi et al., 1987; Smith and Parent, 1988; Crossman, 1989; Chevalier and Deniau, 1990; DeLong, 1990; Fujimoto and Kita, 1992, 1993; Matsumara et al., 1992; Rinvik and Ottersen, 1993; Wichmann et al., 1994; Smith et al., 1998). Our findings indicate that subtha- lamic neurons possess the intrinsic ability to fire rhythmically in the absence of synaptic input, and can perform their function of providing a background excitatory tone to basal ganglia structures in the absence of any specific drive. In response to cortical excitation and/or disinhibition via the globus pallidus, subthalamic neurons also produce transient bursts of driven firing that contribute to the basal ganglia activity that occurs during movement (Kitai and Deniau, 1981; DeLong et al., 1985; Nakanishi et al., 1987, 1988; Smith and Parent, 1988; DeLong, 1990; Fujimoto and Kita, 1992, 1993; Matsumara et al., 1992; Mouroux and Feger, 1993; Rinvik and Ottersen, 1993; Wichmann et al., 1994; Bevan et al., 1995; Mouroux et al., 1995; Clarke and Bolam, 1998; Maurice et al., 1998; Smith et al., 1998). The sigmoidal inputoutput curve of subthalamic neurons makes them relatively insensitive to small changes in input near their resting oscillation but very sensitive to changes in input during high-frequency driven responses. Similar input-output relationships have been described for spinal motoneurons which operate in a similar manner during rest and movement (Kernell and Sjoholm, 1973; Schwindt, 1973; Schwindt and Calvin, 1973; Mauritz et al., 1974; Heyer and Llinas, 1977; Schwindt and Crill, 1977, 1980, 1982). Subthalamic neurons also possess the ability to fire with little spike frequency adaptation for several hundred milliseconds despite the activation of potassium currents that limit spontaneous activity for long periods after current injection. The prolonged action of calcium-dependent potassium currents after activation of the neurons may also have implications for the mechanism of the therapeutic effect of high-frequency subthalamic stimulation in Parkinson's disease (Benazzouz et al., 1993, 1996; Limousin et al., 1995; Gao et al., 1998). The beneficial effects of highfrequency stimulation have been attributed to potential depolarization block of these neurons. However, their ability to fire at very high frequencies in response to intracellular current suggests that they are unlikely to show a substantial depolarization block in the frequency range generally shown to have a therapeutic effect $(100-1000 \mathrm{~Hz} ; 60 \mu \mathrm{sec}$ duration). Our results suggest that the decreased firing of subthalamic neurons seen with this stimulation is attributable to decreased spontaneous firing between episodes of stimulation, caused by accumulation of calcium and calcium-dependent potassium current.

\section{REFERENCES}

Alzheimer C, Schwindt P, Crill W (1993) Modal gating of $\mathrm{Na}^{+}$channels as a mechanism of persistent $\mathrm{Na}^{+}$current in pyramidal neurons from rat and cat sensorimotor cortex. J Neurosci 13:660-673.

Benazzouz A, Gross C, Feger J, Boraud T, Bioulac B (1993) Reversal of rigidity and improvement in motor performance by subthalamic highfrequency stimulation in MPTP-treated monkeys. Eur J Neurosci 5:382-389.

Benazzouz A, Boraud T, Feger J, Burbaud P, Bioulac B, Gross C (1996) Alleviation of experimental hemiparkinsonism by high-frequency stimulation of the subthalamic nucleus in primates: a comparison with L-Dopa treatment. Mov Disord 11:627-632.

Bennett BD, Wilson CJ (1998) Synaptic regulation of action potential timing in neostriatal cholinergic interneurons. $\mathrm{J}$ Neurosci 18:8539-8549.

Beurrier C, Congar P, Bioulac B, Hammond C (1999) Subthalamic neurons switch from single-spike activity to burst-firing mode. J Neurosci 19:599-609.

Bevan MD, Francis CM, Bolam JP (1995) The glutamate-enriched cortical and thalamic input to neurons in the subthalamic nucleus of the rat: convergence with GABA-positive terminals. J Comp Neurol 361:491-511.

Blatz AL, Magleby KL (1987) Calcium-activated potassium channels. Trends Neurosci 10:463-467.

Calvin WH (1978) Setting the pace and pattern of discharge: do CNS 
neurons vary their sensitivity to external inputs via their repetitive firing processes? Fed Proc 37:2165-2170.

Calvin WH, Stevens CF (1967) Synaptic noise as a source of variability in the interval between action potentials. Science 155:842-844.

Calvin WH, Stevens CF (1968) Synaptic noise and other sources of randomness in motoneuron interspike intervals. J Neurophysiol 31:574-587.

Chevalier G, Deniau JM (1990) Disinhibition as a basic process in the expression of striatal functions. Trends Neurosci 13:277-279.

Clarke NP, Bolam JP (1998) Distribution of glutamate receptor subunits at neurochemically characterized synapses in the entopeduncular nucleus and subthalamic nucleus of the rat. J Comp Neurol 397:403-420.

Crill W (1996) Persistent sodium current in mammalian central neurons. Annu Rev Physiol 58:349-362.

Crossman AR (1989) Neural mechanisms in disorders of movement. Comp Biochem Physiol 93A:141-149.

Cummins T, Howe J, Waxman S (1998) Slow closed-state inactivation: a novel mechanism underlying ramp currents in cells expressing the hNE/PN1 sodium channel. J Neurosci 18:9607-9619.

DeLong MR (1990) Primate models of movement disorders of basal ganglia origin. Trends Neurosci 13:281-285.

DeLong MR, Crutcher MD, Georgopoulos AP (1985) Primate globus pallidus and subthalamic nucleus: functional organization. J Neurophysiol 53:530-543.

Fleidervish I, Gutnick M (1996) Kinetics of slow inactivation of persistent sodium current in layer $\mathrm{V}$ neurons of mouse neocortical slices. J Neurophysiol 76:2125-2130.

Fleidervish I, Friedman A, Gutnick M (1996) Slow inactivation of $\mathrm{Na}^{+}$ current and slow cumulative spike adaptation in mouse and guinea-pig neocortical neurones in slices. J Physiol (Lond) 493:83-97.

Foehring RC, Schwindt PC, Crill WE (1989) Norepinephrine selectively reduces slow $\mathrm{Ca}^{2+}$ and $\mathrm{Na}^{+}$-mediated $\mathrm{K}^{+}$currents in cat neocortical neurons. J Neurophysiol 61:245-256.

Fujimoto K, Kita H (1992) Responses of rat substantia nigra pars reticulata units to cortical stimulation. Neurosci Lett 142:105-109.

Fujimoto K, Kita H (1993) Response characteristics of subthalamic neurons to the stimulation of the sensorimotor cortex in the rat. Brain Res 609:185-192.

Gao D, Benazzouz A, Piallat B, Bressand K, Ilinsky I, Kultas-Ilinsky K, Benabid A (1998) High-frequency stimulation of the subthalamic nucleus suppresses experimental resting tremor in monkey. Neuroscience 88:201-212.

Georgopoulos A, DeLong M, Crutcher M (1983) Relations between parameters of step-tracking movements and single cell discharge in the globus pallidus and subthalamic nucleus of the behaving monkey. J Neurosci 3:1586-1598.

Gorelova N, Reiner P (1996) Role of afterhyperpolarization in control of discharge properties of septal cholinergic neurons in vitro. J Neurophysiol 75:695-706.

Greffath W, Martin E, Reuss S, Boehmer G (1998) Components of after-hyperpolarization in magnocellular neurones of the rat supraoptic nucleus in vitro. J Physiol (Lond) 513:493-506.

Hammond C, Yelnik J (1983) Intracellular labelling of rat subthalamic neurones with horseradish peroxidase: computer analysis of dendrites and characterization of axon arborization. Neuroscience 8:781-790.

Hausser M, Clark BA (1997) Tonic synaptic inhibition modulates neuronal output pattern and spatiotemporal synaptic integration. Neuron 19:665-678.

Heyer H, Llinas R (1977) Control of rhythmic firing in normal and axotomized cat spinal motoneurons. J Neurophysiol 40:480-488.

Horikawa K, Armstrong WE (1988) A versatile means of intracellular labeling: injection of biocytin and its detection with avidin conjugates. J Neurosci 25:1-11.

Kang Y, Kitai ST (1993) Calcium spike underlying rhythmic firing in dopaminergic neurons of the rat substantia nigra. Neurosci Res 18:195-207.

Kay A, Sugimori M, Llinas R (1998) Kinetic and stochastic properties of a persistent sodium current in mature guinea pig cerebellar purkinje cells. J Neurophysiol 80:1168-1179.

Kernell D, Sjoholm H (1973) Repetitive impulse firing: comparisons between neurone models based on "voltage clamp equations" and spinal motorneurones. Acta Physiol Scand 87:40-56.

Kim U, McCormick D (1998) Functional and ionic properties of a slow afterhyperpolarization in ferret perigeniculate neurons in vitro. J Neurophysiol 80:1222-1235.

Kita H, Chang HT, Kitai ST (1983) The morphology of intracellularly labeled rat subthalamic neurons: a light microscopic analysis. J Comp Neurol 215:245-257.

Kitai ST, Deniau JM (1981) Cortical inputs to the subthalamus: intracellular analysis. Brain Res 214:411-415.

Limousin P, Pollak P, Hoffman D, Le Bas J, Broussolle E, Perret J, Benabid A (1995) Effect on parkinsonian signs and symptoms of bilateral subthalamic nucleus stimulation. Lancet 345:91-95.

Lorenzon N, Foehring RC (1992) Relationship between repetitive firing and afterhyperpolarizations in human neocortical neurons. J Neurophysiol 67:350-363.

MacGregor R, Sharpless S (1973) Repetitive discharge rate of a simple neuron model with accumulation of after-hyperpolarization conductance. Brain Res 64:387-390.

Marrion N, Tavalin S (1998) Selective activation of $\mathrm{Ca}^{2+}$-activated $\mathrm{K}^{+}$ potassium channels by $\mathrm{Ca}^{2+}$ channels in hippocampal neurons. Nature 395:900-905.

Matsumara M, Kojima J, Gardner T, Hikosaka O (1992) Visual and oculomotor functions of monkey subthalamic nucleus. J Neurophysiol 67:1615-1632.

Maurice N, Deniau JM, Glowinski J, Thierry AM (1998) Relationships between the prefrontal cortex and the basal ganglia in the rat: physiology of the corticosubthalamic circuits. J Neurosci 18:9539-9546.

Mauritz K, Schlue W, Richter D, Nacimiento A (1974) Membrane conductance course during spike intervals and repetitive firing in cat spinal motorneurones. Brain Res. 76:223-233.

Mouroux M, Feger J (1993) Evidence that the parafascicular projection to the subthalamic nucleus is glutamatergic. NeuroReport 4:613-615.

Mouroux M, Hassani OK, Feger J (1995) Electrophysiological study of the excitatory parafascicular projection to the subthalamic nucleus and evidence for IPSI- and contralateral controls. Neuroscience 67:399-407.

Nakanishi H, Kita H, Kitai ST (1987) Intracellular study of rat substantia nigra pars reticulata neurons in an in vitro slice preparation: electrical membrane properties and response characteristics to subthalamic stimulation. Brain Res 437:45-55.

Nakanishi H, Kita H, Kitai ST (1988) An $N$-methyl-D-aspartate receptor mediated excitatory postsynaptic potential evoked in subthalamic neurons in an vitro slice preparation of the rat. Neurosci Lett 95:130-136.

Overton PG, Greenfield SA (1995) Determinants of neuronal firing pattern in the guinea-pig subthalamic nucleus an in vivo and in vitro comparison. J Neural Transm 10:41-54.

Parri R, Crunelli V (1998) Sodium currents in rat and cat thalamocortical neurons:role of a non-inactivating component in tonic and burst firing. J Neurosci 18:854-867.

Paton JF, Rogers WT, Schwaber JS (1991) Tonically rhythmic neurons within a cardiorespiratory region of the nucleus tractus solitarii of the rat. J Neurophysiol 66:824-838.

Pennartz C, Bierlaagh M, Geurtsen A (1997) Cellular mechanisms underlying spontaneous firing in rat suprachiasmatic nucleus: involvement of a slowly inactivating sodium current. J Neurophysiol 78:1811-1825.

Pineda J, Galarraga E, Bargas J, Cristancho M, Aceves J (1992) Charybdotoxin and apamin sensitivity of the calcium-dependent repolarization and the afterhyperpolarization in neostriatal neurons. J Neurophysiol 68:287-294.

Pineda J, Waters R, Foehring RC (1998) Specificity in the interaction of HVA $\mathrm{Ca}^{2+}$ channel types with $\mathrm{Ca}^{2+}$ dependent AHPs and firing behavior in neocortical pyramidal neurons. J Neurophysiol 79:2522-2533.

Raman I, Bean BP (1997) Resurgent sodium current and action potential formation in dissociated cerebellar purkinje neurons. J Neurosci 17:4517-4526.

Raman I, Bean BP (1999) Ionic currents underlying spontaneous action potentials in isolated cerebellar purkinje neurons. J Neurosci 19:1663-1674.

Rinvik E, Ottersen OP (1993) Terminals of subthalamonigral fibres are enriched with gluatamate-like immunoreactivity: an electron microscopic, immunogold analysis in the cat. J Chem Neuroanat 6:19-30.

Sah P (1992) Role of calcium influx and buffering in the kinetics of a $\mathrm{Ca}^{2+}$-activated $\mathrm{K}^{+}$current in rat vagal motorneurons. J Neurophysiol 68:2237-2247.

Sah P (1993) Kinetic properties of a slow apamin-insensitive $\mathrm{Ca}^{2+}$ - 
activated $\mathrm{K}^{+}$current in guinea pig vagal neurons. J Neurophysiol 69:361-366.

Sah, P (1996) $\mathrm{Ca}^{2+}$ activated $\mathrm{K}^{+}$currents in neurones: types, physiological roles and modulation. Trends Neurosci 19:150-154.

Sah P, McLachlan E (1992) Potassium currents contributing to action potential repolarization and the afterhyperpolarization in rat vagal motoneurons. J Neurophysiol 68:1834-1841.

Sanchez D, Ribas J (1991) Properties and ionic basis of the action potentials in the periaqueductal grey neurones of the guinea-pig. J Physiol (Lond) 440:167-187.

Schwartzkroin P (1978) Secondary range spiking in hippocampal neurons. Brain Res 149:247-250.

Schwindt P (1973) Membrane potential trajectories underlying motoneuron rhythmic firing at high rates. J Neurophysiol 36:434-449.

Schwindt PC, Calvin WH (1973) Nature of conductances underlying rhythmic firing in cat spinal motoneurons. J Neurophysiol 36:955-973.

Schwindt P, Crill W (1977) A persistent negative resistance in cat lumbar motoneurons. Brain Res 120:173-178.

Schwindt P, Crill W (1980) Properties of a persistent inward current in normal and TEA injected-injected motoneurons. J Neurophysiol 43:1700-1724.

Schwindt P, Crill W (1982) Factors influencing motoneuron rhythmic firing: results from a voltage-clamp study. J Neurophysiol 4:875-890.

Schwindt PC, Spain WJ, Foehring RC, Stafstrom CE, Chubb MC, Crill WE (1988a) Multiple potassium conductance and their functions in neurons from cat sensorimoter cortex in vitro. J Neurophysiol 59:424-449.

Schwindt PC, Spain WJ, Foehring RC, Chubb MC, Crill WE (1988b) Slow conductances in neurons from cat sensorimotor cortex in vitro and their role in slow excitability changes. J Neurophysiol 50:450-467.

Schwindt PC, Spain WJ, Crill WE (1989) Long-lasting reduction of excitability by a sodium-dependent potassium current in cat neocortical neurons. J Neurophysiol 2:233-244.

Shepard P, Bunney B (1991) Repetitive firing properties of putative dopamine-containing neurons in vitro: regulation by an apamin sensitive $\mathrm{Ca}^{2+}$-activated $\mathrm{K}^{+}$conductance. Exp Brain Res 86:141-150.

Smith Y, Parent A (1988) Neurons of the subthalamic nucleus in primates display glutamate but not GABA immunoreactivity. Brain Res 453:353-356.
Smith Y, Bevan MD, Shink E, Bolam JP (1998) Microcircuitry of the direct and indirect pathways of the basal ganglia. Neuroscience 86:353-387.

Stafstrom C, Schwindt P, Crill W (1982) Negative slope conductance due to a persistent subthreshold sodium current in cat neocortical neurons in vitro. Brain Res 236:221-226.

Stafstrom C, Schwindt PC, Crill W (1984) Repetitive firing in layer V neurons from cat neocortex in vitro. J Neurophysiol 52:264-278.

Stafstrom C, Schwindt, Chubb M, Crill W (1985) Properties of persistent sodium conductance and calcium conductance of layer $\mathrm{V}$ neurons from cat sensorimotor cortex in vitro. J Neurophysiol 53:153-170.

Stuart G, Dodt H, Sakman B (1993) Patch-clamp recordings from the soma and dendrites of neurons in brain slices using infrared video microscopy. Pflügers Arch 423:511-518.

Tanabe M, Gahwiler B, Gerber U (1998) L-type calcium channels mediate the slow $\mathrm{Ca}$-dependent afterhyperpolarization current in rat CA3 pyramidal cells in vitro. J Neurophysiol 80:2268-2273.

Turner RS, Anderson ME (1997) Pallidal discharge related to the kinematics of reaching movements in two dimensions. J Neurophysiol 77:1051-1074.

Vergara C, Latorre R, Marrion N, Adelman J (1998) Calcium activated potassium channels. Curr Opin Neurobiol 8:321-329.

Viana F, Bayliss D, Berger A (1993) Multiple potassium conductances and their role in action potential repolarization and repetitive firing behavior of neonatal rat hypoglossal motoneurons. J Neurophysiol 69:2150-2163.

White J, Sekar N, Kay A (1995) Errors in persistent inward currents generated by space-clamp errors: a modelling study. J Neurophysiol 73:2369-2377.

Wichmann H, Bergman H, DeLong M (1994) The primate subthalamic nucleus. I. Functional properties in intact animals. J Neurophysiol 72:494-506.

Yung WH, Hausser MA, Jack JJB (1991) Electrophysiology of dopaminergic and non-dopaminergic neurones of the guinea pig substantia nigra pars compacta in vitro. J Physiol (Lond) 436:643-667.

Zhang L, McBain C (1995) Potassium conductances underlying repolarization and afterhyperpolarization in rat CA1 hippocampal interneurons. J Physiol (Lond) 488:661-672. 